\title{
Evaluating languages functions in a trilingual setting
}

Ioannis Galantomos ${ }^{1}$, Georgia Andreou ${ }^{2}$, Fotini Anastassiou ${ }^{2}$

${ }^{1}$ Department of Special Education \& Department of Language, Literature and

Culture of the Black Sea Countries, University of Thessaly \& Democritus University

of Thrace, Greece

${ }^{2}$ Depatrment of Special Education, University of Thessaly, Greece

https://doi.org/10.36505/ExLing-2010/03/0014/000134

\begin{abstract}
The aim of this research was to investigate the language functions of trilinguals that live in Greece. This study consisted of personal interviews conducted at a State Evening School in Volos in January 2010 and the participants were between 19 and 24 years old. They were all male and they came from immigrant families of Albanian origin. The study aimed to locate the instances that each one of the languages - L1 Albanian, L2 Greek, L3 English - is used and to record the reasons that make the students use each one of their languages.
\end{abstract}

Key words: trilinguals, language functions, attitudes, immigrants.

\section{Introduction}

According to Tucker (1998), multilinguals are far more compared to monolinguals in the world. Recently there has been rapid interest in studies on the acquisition of a third language, most of them focusing on English, as far as educational contexts, since English and multilingualism have become more and more important due to globalization (Cenoz \& Genesee, 1998). Nevertheless, there has not been much published work on the ever growing number of children who are been brought up as multilinguals which is mainly because of the vast mobility of populations between countries and mixed marriages (Barnes, 2005).

Trilingualism/ multilingualism is a rather recent field of research and thus there are a lot of differentiations on its definition. In fact "trying to reach to a proper definition of multilingualism could be said to be the most demanding problem of current linguistics" (Jessner, 2008). Cenoz \& Genesee (1998) suggest that a person should be defined as trilingual if he can use his three languages to communicate in both oral and written speech. Furthermore, due to the fact that many scholars argue that learning an L3 differs from learning an L2, multilingualism is only used to refer to the learning of more than two languages (Hufeisen, 1998).

Especially during the last decade more and more immigrants have come to Greece to live and work here permanently. The most prominent immigrant community is the Albanian one in Greece. Nowadays, we host the second generation of Albanian immigrants. Therefore, we found it rather important to investigate the languages of Albanian students in Greek

ExLing 2010: Proceedings of 3rd Tutorial and Research Workshop on Experimental Linguistics, 25-27 August, Athens, Greece 
schools. Their languages were L1 Albanian, L2 Greek and L3 English. Their L2 and L3 were taught at school. English is of great interest since it is a world language and the one most widely found in multilingual contexts (Barnes, 2005).

\section{Method}

\section{Participants}

Our sample was composed of thirty students of Albanian origin. All of them were male, aged between fifteen and twenty four years old. They studied at the local State Evening School in Volos and their level in English was approximately B1, according to the Common European Framework of Reference for Languages. Their mid age was 19.3 years old and their mid period of residence in Greece was 12.3 years. The research was contacted through personal interviews, which took place in Volos in January 2010, and each one of the students had to answer to two questions concerning their three languages.

\section{Procedure}

The first question aimed to determine where each one of the languages is used, that is at school, at work, within the family or friend environment.

Question:

1.1. Where do you use Albanian?

1.2. Where do you use Greek?

1.3. Where do you use English?

The second question aimed to record the reasons that make these students to use each one of their three languages.

Question:

2.1. When and why do you use Albanian?

2.2. When and why do you use Greek?

2.3. When and why do you use English?

\section{Results}

The answers that were recorded were teamed according to their common features so that they can be further analyzed: 
Albanian

1.1 At home: $90 \%$

At work: $10 \%$

1.2 To communicate with their family: $65 \%$

To communicate with their friends: $15 \%$

During their visits to Albania: 5\%

To preserve their national identity: $15 \%$

Greek

2.1 At school/ daily life: $94 \%$

At work: $4 \%$

With their family: $2 \%$

2.2 To communicate with their friends: $56 \%$

To communicate at work: $4 \%$

To help family members that can not speak Greek well: $2 \%$

Frequent use contributes to better learning of Greek: $38 \%$

English

1.1 At school: $98 \%$

During their holidays: $2 \%$

1.2 In class: $76 \%$

As a sign of personal progress: $20 \%$

To show off to their compatriots who can not speak English: $4 \%$

\section{Discussion}

The participants of this research stated that they use Albanian at home and a small percentage uses Albanian at work too. This is reasonable since their family speaks their L1 at home, as it is usual in immigrant families, to preserve their inheritance and thus their national identity.

On the question where do they use Greek the majority of the students answered at school. It is likely that both students and their parents regard Greek as the lingua franca of educational advancement in Greece. Cummins (1987) emphasizes on power relations between groups within the school environment and between teachers and students. These power relations are determined to a degree by the very nature of being an L2 learner, whether the learner is adult or child. We could dare extend this to the L3 learners too.

The fact that they believe that if they use Greek more frequently they will learn the language more easily is reasonable. Also, according to Oliver \& Purdie (1998) students perceive that their teachers and peers feel more positively when the environment language is used rather than their L1, in all contexts. 
Regarding English the students stated that they mainly use English at school, which means in class during the English language lesson. English has a limited use due to the very nature of the specific school that this research took place.

Attitudes are determinants of the manner in which students engage in language learning at school, they influence learners' expectations for success (Cummins, 1986) and they play a significant role in students' successful maintenance of L1 (Dopke et al, 1991).

Our research tried to make a small step towards understanding attitudes and language functions of trilingual speakers. Studies on trilingualism/ multilingualism in Greece have been a recent field of research, especially compared to the rest of Europe. Our first attempt was a small scale study and a larger scale study could probably enlighten us more.

\section{References}

Cenoz, J., Genesee, F. 1998. Beyond Bilingualism. Multilingualism and Multilingual Education. Clevedon: Multilingual Matters.

Cummins, J. 1986. Individual Differences in Second Language Learning. London, Edward Arnold.

Cummins, J. 1987. Language development, academic achievement and empowering minority students. In Fradd, S. and Tikunoff, W. (eds.) 1987, Bilingual Education and Bilingual Special Education: A guide for Administrators, 75-97. Boston, College Hill Press.

Dopke, S., McNamara, T.F., Quinn T.J. 1991. Psycholinguistic aspects of bilingualism. In Liddicoat, A. (ed.) 1991, Bilingualism and Bilingual Education, 21-79. Melbourne, NLLIA.

Hufeisen, B. 1998. L3-Stand Der Forschung - Was Bleibt zu tun? In B. Hufeisen and B. Lindemann (eds) Tertiarsprachen: Theorien, Modelle, Methoden. Tubingen: Stauffenburg, 169-185.

Jessner, U. 2008. Teaching third languages: Findings, trends and challenges. Language Teaching 41, 15-56.

Tucker, G.R. 1998. A global perspective on multilingual and multicultural education. In J. Cenoz and F. Genesee (eds) Beyond Bilingualism: Multilingual and Multicultural Education. Clevedon: Multilingual Matters, 3-15.

Oliver, R., Purdie, N. 1998. The attitudes of Bilingual children to their languages. Journal of Multilingual and Multicultural Development, vol.19, No. 3. 